\title{
Mechanical Forces in the Immune System
}

\author{
Morgan Huse \\ Immunology Program Memorial Sloan-Kettering Cancer Center New York, NY 10065
}

\section{Summary}

Leukocytes are capable of completely reorganizing their architecture in a matter of minutes. This structural plasticity, which facilitates their migration and communicative function, also enables them to exert a substantial amount of mechanical force against extracellular matrix and the surfaces of interacting cells. In recent years, it has become increasingly clear that these forces play critical roles in immune cell activation and subsequent effector responses. Here, I review our current understanding of how mechanical force regulates cell surface receptor activation, cell migration, intracellular signaling, and intercellular communication, highlighting the biological ramifications of these effects in various immune cell types.

\section{Introduction}

Signal transduction underpins the activation, regulation, and resolution of protective immune responses, and it also plays a central role in immune dysfunction. Over the past thirty years, scientists have applied the tools of biochemistry, molecular biology, and genetics to investigate these topics in depth. Their efforts have identified networks of secreted ligands, cell surface receptors, intracellular signaling pathways, and transcriptional regulators that coordinately control various aspects of cell behavior. These networks are generally thought of as chemical entities, largely because the components that make them up have been characterized as individual molecules that function through noncovalent molecular interactions and/or enzymatic activity.

Although this chemical conception is not incorrect, it ignores the effects of mechanical force on signaling networks and also the possible influence of signaling networks on the mechanical environment within and outside of the cell. This omission is relevant because the life of an immune cell is intensely physical, characterized by comprehensive morphological change, rapid movement through tight interstitial spaces, adhesion under shear flow, and the formation of dynamic interfaces with other cells. The receptor-ligand interactions that govern cellular function take place in these roiling environments, where they are influenced by cellular motions, bulk fluid flow, and the local stiffness of extracellular matrix. In additional to binding their cognate ligands, many cell surface proteins also interact with the cortical actin cytoskeleton, which effectively couples them physically to each other and also to a variety of intracellular signaling pathways that use the cortex as a platform for assembly. Hence, the molecular machinery involved in signal transduction is well positioned to 
propagate physical information about the extracellular environment into the cell and also to translate biochemical signals in the cytoplasm into physical forces exerted against the environment.

Although the idea that mechanical forces regulate and are regulated by intracellular signaling is not new ${ }^{1}$, it has been difficult to study in the immune system due to problems in applying biophysical approaches to leukocytes, which are non-adherent, structurally plastic, and often quite small. Recent technical advances, however, have enabled investigators to explore the mechanical properties of these challenging cell types in greater depth (see Box 1). As a result, we are beginning to appreciate the myriad ways in which cellular forces influence immune function. This review highlights recent progress in the field. I will briefly discuss how cells generate force, after which I will focus on how force regulates several key aspects of immune cell behavior.

\section{How cells generate and sense force}

Cells exert force against their environment via dynamic cytoskeletal remodeling. In most cases, it is the filamentous actin (F-actin) cytoskeleton that bears the brunt of the mechanical load. The paradigmatic model of F-actin dependent force exertion is the contraction of antiparallel actin filaments by the myosin II motor (Figure 1A). Although myosin II based pulling was initially characterized as the mediator of muscle contraction, it is now clear that it drives shape change in most eukaryotic cells, influencing a range of processes that include adhesion, motility, and division ${ }^{2-4}$. Consistent with this pervasive role, myosin II activity has been implicated in force exertion by multiple immune cell types ${ }^{5-10}$. In principle, force can also be generated by actin polymerization, independent of myosin II (Figure 1B). F-actin nucleators such as the Arp2/3 complex, which catalyzes the formation of branched F-actin arrays, and the formins, which induce linear F-actin cables, play critical roles in shape change during migration and polarity induction ${ }^{11,12}$. Protrusive F-actin-based structures can deform underlying substrates as well as the surfaces of other cells ${ }^{13-15}$, implying that they are capable of transmitting forces. That being said, there have been no unambiguous measurements of actin polymerization-based force exertion at a cellular level. This could be because protrusive forces are quite transient and easily masked by their longer-lived, contractile counterparts.

In order to generate force, both contractile and protrusive F-actin dynamics must be coupled to contacts between the cell and the environment that create frictional drag (Figure 1A-B). The best understood contacts of this kind are focal adhesions, which are large protein assemblies that link cell surface integrins to actin stress fibers ${ }^{16,17}$. Focal adhesions display a stereotyped architecture in which integrins and F-actin are bridged by a specialized layer of scaffolding proteins that regulate integrin affinity, F-actin crosslinking, and mechanosensing ${ }^{17,18}$. These structures are readily observed in cultured adherent cells, such as fibroblasts, which use them to anchor their cortex to matrix proteins immobilized on plastic or glass. Focal adhesions require force exertion for their growth and maintenance ${ }^{19-22}$; consequently, they shrink in the absence of myosin contractility, and they are less apparent on softer substrates. Indeed, classical focal adhesions are difficult to find in vivo $^{23}$, where extracellular matrix is more pliable. That being said, adhesion-like structures 
have been documented in certain tissues, implying that the organizational features observed in vitro may indeed be physiologically relevant ${ }^{23}$. Interestingly, many immune cells do not form classical focal adhesions in vitro or in vivo, a feature that possibly reflects their structural plasticity. They do form more transient adhesive contacts, however, that contain cell surface receptors, F-actin, and some of the intracellular machinery typically found in focal adhesions ${ }^{24-26}$. These structures likely serve as anchor points for force exertion during migration and cell-cell contact formation.

Over the past decade, it has become clear that cells sense the mechanical properties of their environment and use the information they acquire to inform gene expression and cell fate decisions. Cells do this by translating the physical perturbations experienced by their constituent proteins into chemical signals, a process known as mechanotransduction ${ }^{27,28}$. At the heart of any mechanotransduction pathway is a molecule whose structure and/or activity is modulated by force. Mechanosensitive channels of the Piezo family, for example, undergo activating conformational change in response to membrane stretch, thereby coupling cell tension to ion flux ${ }^{29-31}$ (Figure 1C). Force-induced conformational changes can also reveal cryptic binding sites within a mechanosensitive protein, leading to the nucleation of signaling complexes (Figure 1D). Mechanical stretching of the scaffolding protein talin, for example, promotes focal adhesion assembly by exposing surfaces that interact with the adaptor vinculin ${ }^{32,33}$. Force can also influence intracellular signaling by changing the strength of protein-protein interactions. Most biomolecular contacts behave as "slip-bonds", which become weaker under applied force. Certain mechanosensitive interactions, however, exhibit increased lifetime under tension, the defining feature of a "catch-bond" 34,35 . As detailed below, catch bond formation is emerging as a central player in leukocyte migration, cell-cell contact formation, and antigen recognition.

It is important to note that force exertion and mechanotransduction are tightly linked processes. Mechanically induced conformational changes only occur under applied force. Hence, effective mechanotransduction requires that a cell exert force on its environment or receive force either from bulk flow or from a closely interacting cell. Conversely, force exertion is itself regulated by feedback from mechanosensing pathways. Adherent cells and lymphocytes, for example, require myosin-based contractility to sense extracellular matrix stiffness ${ }^{36-39}$. They also modulate their contractile forces to match matrix properties, exerting stronger forces on stiffer surfaces and weaker forces on softer ones ${ }^{5,33,40-42}$. The mechanical life of a cell is therefore dependent on continuous cytoskeletal remodeling and signal transduction.

\section{Leukocyte movement}

\section{Two-dimensional migration}

Over the past decade, studies in a multiple systems have revealed how forces originating from within and outside of the migrating cell fundamentally enable and also continuously regulate the molecular machinery involved in movement. The simplest and perhaps best understood of these experimental systems is leukocyte crawling on a 2D matrix. In this context, attachment to the surface is mediated by integrin binding to immobilized matrix proteins or adhesion molecules ${ }^{43}$. Some integrins (e.g. $a_{M} \beta_{2}, a_{x} \beta_{2}$ ) can also bind directly to 
denatured proteins or even uncoated plastic ${ }^{44,45}$. Lymphocytes and neutrophils migrating in 2D adopt an elongated morphology containing an F-actin-rich lamellipodium at the leading edge followed by a trailing, tail-like uropod (Figure 2A). Forward propulsion in adhesive environments is generated by retrograde flow of F-actin against integrin adhesions located at the base of the lamellipodium or further back in the cell body ${ }^{17,46,47}$. Retrograde flow is caused both by actin polymerization against the plasma membrane, which drives the growing fibers backwards ${ }^{48-50}$, and by myosin II contractility, which collapses the leading edge F-actin network into linear bundles ${ }^{17,51,52}$. Myosin II also contributes to migration by retracting the uropod from the matrix as the cell moves forward ${ }^{53,54}$.

Integrins are heterodimeric proteins comprising one $\alpha$ and one $\beta$ chain. Each subunit contains a long extracellular stalk that binds to ligand, a transmembrane helix, and a short intracellular tail that interacts with cytoplasmic signaling and cytoskeletal proteins ${ }^{55}$. In their resting, low affinity state, integrins adopt a bent conformation in which their ligand binding pockets are oriented toward their own plasma membrane. "Inside-out" signaling from inside the cell can induce the extension of the extracellular domain, facilitating ligand recognition ${ }^{56}$. Peak binding affinity, however, is only achieved under applied tangential force, which originates from the actin cytoskeleton and is transferred to the integrin via interactions between cytoskeletal adaptors such as talin and the tail of the $\beta$ subunit $^{57-59}$ (Figure 2B). Pulling force separates the $\alpha$ and $\beta$ tails, inducing a conformational change in the $\beta$ stalk domain that increases its affinity for ligand 100 -fold. Over the past decade, biophysical experiments have directly quantified this catch bond behavior. The $a_{5} \beta_{1}$ integrin, for example, achieves maximal affinity for fibronectin at $30 \mathrm{pN}$ applied force ${ }^{60}$, while $\alpha_{L} \beta_{2}$ (also called LFA1) and $a_{M} \beta_{2}$ (Mac1), function optimally at $10-15 \mathrm{pN}^{61,62}$.

During 2D migration, coupling between retrograde flow and integrin adhesion is not absolute. Varying degrees of slippage are typically observed, leading many to characterize the F-actin-talin-integrin system as a "molecular clutch"63. Recent studies have demonstrated that this clutch regulates motility by adjusting F-actin dynamics to fit the prevailing adhesive conditions ${ }^{46}$. When dendritic cells (DCs) migrate on highly adhesive surfaces, for instance, the clutch is fully engaged and the cells exhibit tight coupling between protrusive actin polymerization and forward motion. By contrast, on low adhesion substrates, strong retrograde F-actin flow is observed, indicative of slippage. Interestingly, DCs compensate for this slippage by increasing the rate of actin polymerization. Ultimately, this enables them to move at equivalent speeds on both strongly and weakly adhesive matrix. As DCs cross from one substrate to another, retrograde flow changes to match the level of clutch engagement. This system relies on the capacity of integrins to function as bidirectional mechanosensors. Retrograde flow unleashes integrin catch bond activity by applying lateral tension to the $\beta$ subunit. The level of subsequent matrix adhesion then feeds back from integrins to the F-actin cytoskeleton to modulate the rate of actin polymerization. The talin-integrin clutch facilitates more efficient migration in two ways. First, it localizes strong adhesive contacts only to regions that contain both strong matrix deposition and active F-actin protrusion. This prevents creation of unnecessary adhesions that do not contribute to and that may actually impede locomotion. Second, application of the clutch limits the use of rapid actin polymerization, which is energetically costly, only to those regions where it is absolutely necessary. 
As cells strain against adhesions to move forward, they exert force against the underlying matrix. A number of labs have applied traction force microscopy (TFM, see Box 1) to measure these forces directly. These studies have revealed intriguing differences between leukocyte cell types. In neutrophils, force exertion concentrates in the rear, near the boundary between the cell body and the uropod ${ }^{9,64}$. Extended, fully activated integrins also cluster in this region ${ }^{65,66}$. The same pattern of integrin activation is seen in migrating $\mathrm{T}$ cells ${ }^{24}$, implying a similar force profile. By contrast, in macrophages and DCs, peak traction forces are observed near the front of the advancing cell ${ }^{67,68}$. This suggests a profile more similar to fibroblasts and endothelial cells, which form strong integrin-mediated adhesions at the base of their lamellipodia ${ }^{17,43}$. Thus, although the integrin-talin clutch drives motility in all leukocytes, precisely where the clutch is engaged differs. Neutrophils and lymphocytes apply a "rear-wheel drive" mechanism, while macrophages and DCs exhibit "front-wheel drive" behavior. It is tempting to speculate that rear wheel drive is a defining characteristic of more dynamic and motile cells that form less stable contacts with their surroundings and change direction quickly.

Directionally persistent movement depends on the maintenance of migratory cell polarity. Recent studies have identified plasma membrane tension as a crucial regulatory parameter. The plasma membrane has the properties of a 2D liquid, and the rapid diffusion of its constituent lipids ensures that tensional changes in one region can propagate almost instantaneously to distal domains ${ }^{69}$, enabling rapid transmission of physical information from one side of the cell to another. Leading edge actin polymerization increases membrane tension by pushing against the plasma membrane. In migrating neutrophils, this tensional increase was shown to inhibit F-actin growth at the sides and back of the cell, blocking the formation of alternative leading edges and thereby maintaining polarity ${ }^{70}$. Tensioned membrane inhibits actin polymerization in at least two ways. First, it functions as a physical barrier that stalls filament growth, especially in regions where filament density is low ${ }^{71}$. Second, it also activates phospholipase D2 (PLD2), which in turn stimulates the mammalian target of rapamycin complex 2 (MTORC2 $)^{72}$. This mechanosensing pathway ultimately inhibits actin polymerization by blocking membrane recruitment of WAVE2, a protein complex that stimulates F-actin growth via Arp2/3. Mathematical modeling suggests that each of these feedback mechanisms has a distinct function in regulating F-actin ${ }^{72}$. PLD2MTORC2 signaling resolves competition between competing cell fronts, while the direct physical inhibition of filament growth is critical for organizing leading edge formation. Despite these new insights, how cells coordinate physically distant components during migration remains poorly understood, and will likely be an exciting area for future investigation.

\section{Leukocyte rolling}

Blood vessels and lymphatics serve as essential conduits for the long-range transport of immune cells. In order to exit these compartments, leukocytes must adhere to vessel walls. One might expect that the strong shear forces resulting from fluid flow in these contexts would impede leukocyte adhesion and subsequent migration. Studies have shown, however, that shear plays an essential role in the localized activation of adhesive molecules. This process is best understood for selectins, which mediate attachment to glycoproteins and 
other glycoconjugates ${ }^{73}$. These interactions induce leukocyte rolling over endothelial surfaces in the direction of flow. It has been known for some time that optimal selectin dependent adhesion requires shear force ${ }^{74,75}$. The underlying basis for this behavior is now thought to be selectin catch bonds (Figure 2C). Pioneering studies of single receptor-ligand interactions using atomic force microscopy (AFM) and the controlled application of microscopic shear forces initially revealed that selectins form catch bonds with a force optimum of $<20 \mathrm{pN}^{76}$. Subsequently, detailed measurements of leukocyte rolling in flow chambers containing varying ligand densities, flow rates, and fluid viscosity indicated that selectin catch bonds keep rolling speed constant at or below optimal shear force; higher levels of flow, however, are able to overcome these catch bonds and increase rolling speeds ${ }^{77}$. Selectin-induced rolling enables leukocytes to probe the endothelial surface for chemokines, which induce inside-out integrin activation leading to the full arrest of the leukocyte on the vessel wall ${ }^{78,79}$. It is generally thought that catch bond formation is crucial for integrin-mediated adhesion in this context, as well (Figure 2C). Indeed, shear has been observed to enhance integrin adhesion in T cells ${ }^{59,80}$. This enhanced activity, however, has not as yet been directly attributed to catch bond formation. Nevertheless, the interpretation makes sense given that integrins are known to form catch bonds and have been observed to undergo force dependent conformational transitions in other systems $57,60,61,81,82$.

The formation of shear-induced selectin and integrin catch bonds provides an elegant mechanism for precise spatiotemporal regulation of adhesion under flow. In this regime, high affinity contacts only form at interfaces that are exposed to shear force, which presumably inhibits unnecessary cell clumping and also prevents arrest in low flow areas, such as capillaries. The mechanical manipulation of adhesive bonds may also provide directional information, enabling migrating cells to polarize appropriately with respect to blood flow. Investigating these hypotheses will require molecular perturbations that allow investigators to eliminate or enhance catch bond formation in complex systems. Interestingly, point mutations have been identified that switch specific selectin-ligand interactions from catch bonds to slip bonds, and vice versa ${ }^{83,84}$. It will be interesting to see if mutations like these alter migratory behavior in vivo.

\section{Three-dimensional migration}

Immune cells move through a variety of mechanically distinct 3D environments in vivo, and they presumably require a correspondingly unique set of mechanobiological mechanisms to navigate through each one. Unfortunately, our understanding of these mechanisms is currently limited by our ability to make biophysical measurements in living tissues. Some progress has been made, however, using in vitro systems that model specific mechanical features of more complex settings.

Following tight adhesion to vessel walls, leukocytes must extravasate through the endothelium to access the surrounding tissue. Leukocytes egress through intercellular spaces between adjacent endothelial cells (the paracellular route) and also by burrowing through pores that form in individual endothelial cells (the transcellular route) ${ }^{85}$. Transit via either of these paths is associated with dramatic shape changes. Leukocytes initially form F-actin-rich protrusive structures, also called invadosome like protrusions (ILPs), which palpate the 
surface of the endothelium, presumably in search of cell-cell boundaries and other permissive regions ${ }^{14,86}$. ILPs serve as initiating structures for trans endothelial migration, interdigitating between adjacent endothelial cells (in the case of paracellular transit) or inducing an invagination in the endothelial cell surface (for transcellular transit) (Figure 2D). The remainder of the cell subsequently follows the ILP through the pore, adopting an extended configuration well suited for squeezing through tight spaces.

Although it stands to reason that mechanical force is critical for this highly distortive process, its precise role has been difficult to tease out largely because the endothelium is not a passive participant. To facilitate transmigration, endothelial cells undergo coordinated changes in intracellular signaling, cytoskeletal architecture, and adhesion molecule expression, which reduce their barrier properties and enhance their interactions with leukocytes ${ }^{85,87}$. Indeed, it can be argued that, under inflammatory conditions, endothelial cells form a path for leukocyte transmigration and pave it with permissive ligands. Accordingly, studies aimed at discerning the role of force in this context must necessarily include an endothelial monolayer. To address this issue, an imaging-based biophysical system was developed in which a confluent monolayer of endothelial cells was grown on top of an array of deformable micropillars (see Box 1$)^{88}$. Distortions of the endothelium induced by neutrophil diapedesis resulted in deflection of the pillars beneath, enabling quantification of associated forces. In this manner, it was shown that transmigrating neutrophils exert strong lateral forces, on the order of $60 \mathrm{nN}$ per cell. Interestingly, peak force exertion was not correlated with initial pore formation, but rather with cell body transit through the pore (Figure 2D). Hence, while mechanical force may not be required for generating a transmigration path, it appears to be crucial for squeezing the less deformable components of the neutrophil through it. Indeed, recent studies have demonstrated that cells must employ particularly strong forces to extrude their nuclei through narrow spaces ${ }^{89,90}$. The capacity of this squeezing to induce DNA damage has been documented ${ }^{91,92}$. Transmigration also promotes leukocyte maturation ${ }^{85,87}$, and it is tempting to speculate that extravasation forces and mechanosensing pathways might contribute to this process.

After extravasation from vessels, leukocytes migrate through a diverse array of 3D environments. Studies suggest that motility mechanisms may vary substantially depending on the cell type and the properties of the surrounding matrix (Figure 2E). In certain contexts, cells adopt an alternative mode in which actin-hypodense blebs are projected forward by actomyosin-based forces originating in the back of the cell ${ }^{43,93}$. These blebs then acquire actin and form adhesions to the substrate, effectively advancing the cell through the matrix. This rear-wheel drive mechanism contrasts starkly with the front-wheel drive character of leading edge-driven migration, and it may have substantial functional consequences for certain cell types. DC migration through 3D microchannels, for instance, largely depends on formin-dependent actin polymerization and myosin contractility in the rear of the cell ${ }^{94,95}$. This enables the DC to devote its leading edge to endocytosis, which is crucial for antigen capture and presentation. The tight spatial confinement inherent to migration in $3 \mathrm{D}$ also makes specific adhesive interactions less important for motility. This is borne out by in vivo analysis of integrin deficient leukocytes, which migrate normally through many tissues despite exhibiting profound defects in diapedesis ${ }^{8}$. Additional studies have suggested that friction between cellular interdigitations and the surrounding matrix can provide 
counterforces sufficient to enable propulsion without molecularly specific adhesive contacts $^{46,96}$ (Figure 2E). In retrospect, the focus on canonical, adhesion-based motility likely reflected our dependence on 2D systems in which cells must bind strongly to the surface to avoid being swept away by currents in the medium. Indeed, under conditions of high viscosity and consequently low current flow, it has been shown that 2D lymphocyte migration switches from standard leading edge propulsion to a "walking" mode characterized by transient, myosin rich contacts with the surface ${ }^{97}$.

Further progress in our biophysical understanding of interstitial migration will require robust strategies for measuring forces in 3D. Unfortunately, standard TFM substrates, like polyacrylamide, are impenetrable to migrating cells, and more physiologically relevant matrices, like collagen, form heterogeneous, irregular structures that are difficult to analyze using standard approaches. The problem is particularly acute for leukocytes, which are small and highly motile. Recent methodological developments for quantifying cell movement and matrix distortions by $3 \mathrm{D}$ TFM provide possible strategies for addressing this issue ${ }^{98,99}$. One could also imagine developing an approach in which fluorescent tension sensing probes (see Box 1) are incorporated into matrix proteins. Visualizing the pattern of force exertion in 3D will provide important insights into why leukocytes utilize specific migration strategies in certain environments and how these strategies contribute to other aspects of their function.

\section{Immune Cell-Cell Interactions}

\section{Lymphocyte activation}

$\mathrm{B}$ cells and T cells recognize cognate antigens predominantly on the surfaces of other cells, either as immobilized whole protein in the case of B cells, or as short peptides bound to major histocompatibility complex (MHC) molecules in the case of T cells. Engagement of antigenic ligands by the B cell or T cell antigen receptor (BCR and TCR, respectively) rapidly induces robust intracellular signaling responses, leading within minutes to the formation of an immunological synapse between the lymphocyte and the antigen-presenting cell (APC). Classical immunological synapses are defined by a stereotyped concentric architecture in which a central cluster of antigen receptor is surrounded by concentric, annular accumulations of integrins and F-actin ${ }^{100,101}$ (Figure 3A). This organization promotes strong adhesion to and cytoskeletal polarization toward the APC, and it also excludes inhibitory molecules like the phosphatase CD45. Immunological synapses can persist for hours, and they represent the cell biological context in which $\mathrm{T}$ cells and $\mathrm{B}$ cells undergo activation and mount effector responses.

It is now well established that lymphocyte activation is a mechanosensitive process. This property was initially documented by experiments in which $\mathrm{T}$ cells and $\mathrm{B}$ cells were stimulated on deformable matrices coated with activating ligands ${ }^{39,102-104}$. In general, lymphocytes exhibited stronger signaling responses and cytokine secretion on stiff surfaces compared to their softer counterparts, consistent with the idea that antigen receptors pull against their ligands to achieve optimal signaling capacity. Interestingly, peak ligand-induced proliferation was observed at intermediate, rather than high, levels of substrate stiffness. Although the basis for this discrepancy remains unclear, it is possible that the robust signaling observed at high stiffness triggers activation induced cell death, which could 
adversely affect lymphocyte expansion. Nevertheless, these studies made it clear that the mechanical properties of antigen-presenting surfaces strongly influence lymphocyte activation.

The molecular basis for this mechanosensitivity has been traced back to the antigen receptors themselves. Pioneering optical trap experiments initially suggested that the TCR is sensitive to mechanical manipulation ${ }^{105}$. Subsequently, it was found that the TCR, similar to selectins and integrins, forms ligand-induced catch bonds ${ }^{106,107}$. These studies relied on innovative biomembrane force probe and optical trap systems in which constant piconewton scale forces could be applied to single receptor ligand interactions (see Box 1). In this manner, it was shown that bond lifetimes for agonist peptide-MHC (pMHC)-TCR interactions are maximal at $\sim 10 \mathrm{pN}$ of applied force. This was associated with more robust and long-lived TCR-induced $\mathrm{Ca}^{2+}$ flux, suggesting that catch bond formation is required for stronger $\mathrm{T}$ cell activation. By contrast, mutated pMHC ligands with less stimulatory activity exhibited more rapid dissociation from the TCR with increasing force, indicative of slip bond behavior. One of the outstanding questions in the field of lymphocyte signaling is how $\mathrm{T}$ cells discriminate between bona fide antigens and self-derived peptides, particularly in situations where self pMHC differs in its affinity for the TCR by less than an order of magnitude. These studies addressed this quandary by demonstrating that, by activating catch bonds, applied force can enhance the discriminatory power of TCR recognition as much as 15 -fold.

Force exertion may also play a critical role in transforming ligand binding by the TCR into the phosphorylation of its associated CD3 signaling chains. Studies indicate that, in the unphosphorylated state, the cytoplasmic tails of the CD3 complex associate with the inner leaflet of the plasma membrane, effectively shielding their immunotyrosine-based activation motifs (ITAMs) ${ }^{108,109}$. Ligand binding by the TCR induces conformational changes in the CD3 chains that expose these ITAM motifs, allowing them to be phosphorylated by Srcfamily kinases ${ }^{110,111}$ (Figure 3B). The phosphorylated ITAMs can then be bound by the Syk-family kinase Zap70, which propagates signals downstream. Although definitive studies have not, as yet, directly linked mechanical force to conformational changes within CD3, an intriguing experiment using stimulatory antibodies against the TCR suggests that this might be the case ${ }^{107}$. Although they bind very tightly, anti-TCR antibodies form slip bonds that decrease in lifetime with increasing tension. Nevertheless, when TCRs bind to these antibodies, they display peak signal transduction at $10 \mathrm{pN}$ of applied force. This result implies that force can promote TCR activation independent of catch bond formation, possibly by driving conformational change.

The mechanosensitive properties of the BCR were explored extensively in a recent study in which surface bound antigen was presented to B cells attached to tension gauge tethers (TGTs) ${ }^{112}$. Each TGT contains a DNA duplex whose rupture force depends on the pattern and extent of its base-pairing (see Box 1). It was found that antigens attached to easily ruptured tethers ( $\leq 16 \mathrm{pN}$ ) failed to stimulate naïve B cells. By contrast, moderately tethered $(23-43 \mathrm{pN})$ antigen induced measurable levels of signaling, while strongly attached (> 50 $\mathrm{pN}$ ) antigen caused robust $\mathrm{B}$ cell activation. These results indicated that a tensioned BCR is a prerequisite for activation, although they left unresolved whether tension functions by 
increasing the strength of ligand binding, enhancing signal transduction, or both. Interestingly, whereas high levels of tension were critical for full activation of IgM, the isotype expressed by naïve B cells, neither IgG nor IgE, which are expressed by memory B cells, depended on force exertion for signaling. It is tempting to speculate that these differences in mechanosensitivity reflect the functional properties of each cell type. Setting a force threshold for IgM activation would presumably prevent naïve B cells from mounting autoreactive responses against suboptimal self-antigens. This sort of mechanical checkpoint would presumably be less important for memory cells, which express optimized $\operatorname{IgG}$ and $\operatorname{IgE}$ that are highly specific for cognate antigen.

It is generally thought that F-actin dynamics within the immunological synapse apply the forces required for the activation of mechanosensitive receptors (Figure 3B). Upon ligand binding, TCRs and BCRs coalesce into signaling microclusters containing $>10$ receptors each $^{113}$. These clusters are then swept toward the center of the contact by retrograde F-actin flow at the periphery and then by myosin II dependent actin arcs closer to the center ${ }^{113,114}$. Disruption of centripetal trafficking inhibits TCR signaling from microclusters within seconds ${ }^{113}$, implying that force exertion is essential for maintaining receptor activation. Recent studies have demonstrated that TCR microclusters assemble at the tips of actin rich protrusive structures that also require the actin nucleation promoting factor $\mathrm{WASp}^{115,116}$. These protrusions bear striking similarities with the ILPs that have been documented in T cell-endothelial cell contacts ${ }^{86}$, and some have speculated that they are identical structures ${ }^{116}$. Regardless of their precise classification, they appear to promote signaling by enabling the T cell to penetrate the APC glycocalyx and thereby bring its TCRs into close apposition with pMHC ligands ${ }^{115}$.

Synaptic F-actin dynamics are also crucial for the activation of LFA1, the predominant integrin on T cells and B cells, which binds tightly to the adhesion molecules ICAM1 and ICAM2. LFA1 plays an essential role in lymphocyte activation by mediating tight adhesion to the target cell and then transducing outside-in signals that enhance effector responses ${ }^{117}$. Perturbations that arrest retrograde flow reduce the accumulation of high affinity, extended LFA-1 within the immunological synapse and also compromise the capacity of $\mathrm{T}$ cells to bind strongly to ICAM ${ }^{118}$. Hence, the adhesiveness of the synapse largely depends on its dynamic structure. Interestingly, it appears that APCs can also contribute mechanically to integrin-mediated adhesion at the synapse. In a recent study, fluorescence recovery after photobleaching (FRAP) analysis revealed that DCs immobilize a substantial fraction of their cell surface ICAM $1^{119}$. This was shown to enhance the mechanical effects of retrograde Factin flow on the $\mathrm{T}$ cell side of the synapse by providing a strong counterforce for integrins under tension (Figure 3B). This discovery is quite groundbreaking because it suggests that cells can regulate intercellular communication by modulating the physical status of the signaling molecules in question, and not just their expression level or localization pattern. It will be interesting to explore the extent to which this paradigm applies to other receptorligand systems in other immune cell types.

Although studies of immunological synapse formation have largely focused on lymphocytes, it is important to note that other immune cell types, including innate lineages, also form highly organized interfaces in response to activating stimulation. One of the most interesting 
of these contacts, from a mechanical perspective, is the phagocytic cup used by macrophages and other innate leukocytes to internalize large particles ${ }^{120-122}$. The phagocytic cup and the immunological synapse are both bounded by a peripheral ring of F-actin that drives lamellipodial growth, and both structures often exhibit an annular accumulation of activated $\beta_{2}$ integrins. Recently, it was also shown that phagocytic contacts exclude CD45 ${ }^{123}$. These structural similarities imply analogous ontogeny, and indeed, many phagocytic receptors, including the C-type lectin Dectin1 and multiple Fc receptors, contain ITAM or ITAM-like motifs that drive phosphotyrosine signaling through Src- and Syk-family kinases ${ }^{120}$. As with lymphocyte synapses, these ITAM dependent signals drive actin remodeling and inside-out integrin upregulation, leading to the formation of an ordered, adhesive contact. Given these parallels, a role for mechanotransduction in the phagocytic synapse seems probable. Indeed, the application of biophysical techniques initially applied to T cell and B cell systems have begun to shed light on the mechanical properties of phagocytic recognition. The BFP approach, for instance, has been used to analyze the catch bond behavior of the phagocytic integrin Mac1 ${ }^{62}$. Recent work has also revealed that catch bonds formed between the bacterial adhesin FimH and the glycoprotein CD48 play a critical role in macrophage uptake of E. Coli ${ }^{124}$. Phagocytes can internalize particles with a wide range of sizes, shapes, and rigidities. In this context, mechanosensitivity is likely to be crucial for phagocytic receptors, which must effectively tune the physical properties of the recognition and internalization response to those of the target particle.

\section{Effector responses}

Many of the functional responses that mediate immunity occur in the context of immunological synapses, and recent studies have begun to explore the extent to which they are influenced by synaptic forces. This section will cover three systems in which force modulates the effector phase: antigen extraction by B cells, particle internalization during phagocytosis, and target cell killing by cytotoxic T lymphocytes (CTLs).

After binding to cognate antigen, B cells internalize it for processing and presentation to $\mathrm{CD}^{+} \mathrm{T}$ cells. The $\mathrm{T}$ cells then provide stimulatory cytokines and cell surface ligands that "help" the B cells differentiate into antibody secreting effectors. To ensure that only the appropriate B cell clones are selected and expanded, it is crucial that the extraction process internalizes only bona fide, high affinity antigen. Recent studies have revealed that B cells apply a mechanical threshold to accomplish this task. To observe the extraction process directly, B cells were imaged on membrane sheets coated with cognate antigen ${ }^{7}$. In this context, the B cells pulled BCR clusters containing associated antigens into deep invaginations within the synapse (Figure 3C). The formation of these invaginations, which depended on myosin contractility, was a prerequisite for subsequent clathrin-mediated endocytosis. These observations suggested that only antigen clusters with a high enough affinity to remain attached to the BCR during invagination could be effectively internalized. Consistent with this idea, it was found that blocking invagination formation with a myosin inhibitor not only reduced total extraction, but also eliminated the capacity of B cells to discriminate between high and low affinity antigen. 
After activation, a subset of B cells move into germinal centers (GCs), where they undergo iterative rounds of somatic hypermutation in order to enhance BCR affinity ${ }^{125}$. During this process, successfully evolving B cells are selected based on their ability to extract antigen from the surface of follicular DCs and present it to follicular helper T cells. Given that the objective of somatic hypermutation is to generate receptors of even higher affinity, it stands to reason that antigen extraction in GC B cells might be subject to a higher mechanical threshold than in naïve B cells. Indeed, GC B cells appear to organize their synapses differently than their naïve counterparts, trafficking antigen into smaller peripheral clusters rather than larger, centralized ones ${ }^{126}$. This limits the number of engaged BCRs in each cluster, reducing their overall avidity and thereby increasing the mechanical demands on each individual receptor. Using DNA-based fluorescent tension sensors (see Box 1), it was also shown that GC B cells exert higher extraction forces than naïve B cells ${ }^{126}$. Taken together, these results indicate that the mechanical antigen internalization threshold can be regulated to optimize the functionality of distinct $B$ cell subsets.

Phagocytosis requires distortion of the plasma membrane and underlying cytoskeleton, and it can also involve the forcible separation of the engulfed particle from its extracellular environment. It is generally thought that myosin contractility plays some role in the process, but how and where it comes into effect is unclear ${ }^{120}$. One might imagine that myosin could promote uptake by driving retrograde pulling of integrins and other phagocytic receptors coupled to the F-actin cytoskeleton. This would have the effect of dragging the particle into the cell. Myosin II, which participates in the centripetal flow of integrins in the T cell immunological synapse, would appear to be a good candidate for such a process. Consistent with this idea, inhibitor-based experiments have suggested a role for myosin II in both Fc and complement-mediated phagocytosis ${ }^{127,128}$. Whether myosin II functions in this context by driving retrograde flow of surface receptors, however, is not known. Myosin contractility could also promote internalization by mediating purse string-like contraction at the periphery of the phagocytic cup, thereby by closing the plasma membrane over the particle. Studies have suggested that monomeric class I myosins may be involved in this kind of process ${ }^{129,130}$. Both myosin $1 \mathrm{G}$ and myosin $1 \mathrm{C}$ have been localized to phagocytic cups, and myosin $1 \mathrm{C}$, in particular, accumulates near the distal edges of the lamellipodia as they constrict around the particle. Myosin X, an atypical isoform that contains lipid binding $\mathrm{PH}$ domains, has also been implicated in phagocytosis ${ }^{131}$. This protein is particularly interesting because it binds specifically to phosphatidylinositol trisphosphate $\left(\mathrm{PIP}_{3}\right)$, a lipid second messenger that is crucial for particle uptake ${ }^{120}$. Deciphering the choreography of these myosin isoforms and establishing their respective roles will require more specific loss-offunction approaches coupled to high-resolution imaging methods.

Membrane tension has recently been implicated as an important regulator of phagocytosis ${ }^{132}$. Macrophages hold $20-40 \%$ of their surface area in reserve as plasma membrane folds. Phagocytic synapse formation exhausts these folds, leading to a rapid increase in membrane tension as the cup reaches maximal size. This tensional spike was shown to induce the reorganization of synaptic F-actin and also to drive a switch from synapse growth to particle internalization. This switch was associated with the exocytosis of new membrane into the phagocytic cup. Interestingly, although tension-induced exocytosis was shown to be required for particle internalization, myosin activity was dispensable. It is 
difficult to imagine how membrane insertion at the base of the phagocytic cup could drive internalization on its own, in the absence of at least some purse string contractility. Phagocytosis is a diverse process, however, and internalization mechanisms could vary widely depending on the size of the particle, its stiffness, and the set of receptors it engages.

CTLs destroy target cells by secreting a toxic mixture of the hydrophobic protein perforin and several granzyme proteases. Perforin forms pores in the target cell membrane, inducing a membrane damage response that enables granzymes to access the cytoplasm, where they induce apoptosis ${ }^{133,134}$. Cytolytic molecules are secreted directionally into the immunological synapse, which is thought to enhance the potency and specificity of target cell killing by restricting the scope of perforin and granzyme diffusion ${ }^{135}$. Recent work has revealed that the mechanical activity of the synapse also plays a critical role in potentiating cytotoxicity. This discovery was enabled by the adaptation of single cell biophysical approaches to measure synaptic forces. Using both standard gel-based TFM and a higher resolution approach in which cells are imaged on arrays of deformable micropillars (see Box 1), it was found that $\mathrm{T}$ cells exert nanonewton scale forces against antigen presenting surfaces ${ }^{136}$. Similar observations were made by kymographic analysis of movies in which individual $\mathrm{T}$ cells were presented with stimulatory beads attached to micropipettes ${ }^{6}$. Application of these systems to CTLs revealed an intriguing correlation between cytotoxicity and synaptic force exertion. Previously, it had been shown that phosphoinositide 3-kinase (PI3K) signaling through the exchange factor Dock2 was critical for both TCRinduced F-actin remodeling and target cell killing ${ }^{137}$. Interestingly, whereas loss- and gainof-function perturbations in the PI3K-Dock2 pathway dramatically altered cytotoxicity, they had no effect on lytic granule release. These results implied a physical role for the synapse in target cell killing. Consistent with this idea, it was found that CTLs lacking Dock2 exerted less synaptic force, while CTLs with increased PI3K-Dock2 signaling exerted much more ${ }^{6}$.

Amplification of the PI3K-Dock2 pathway dramatically accelerated perforin pore formation in the target cell, suggesting a link between synaptic force and perforin function. Prior studies had suggested that the pore forming activity of hydrophobic proteins like perforin could be enhanced by the application of tension to the target membrane ${ }^{138-140}$. Consistent with this idea, chemical perturbations that increased target cell membrane tension increased perforin pore formation, and vice versa ${ }^{6}$. Furthermore, adherent target cells grown on stiff polyacrylamide hydrogels, which displayed a stellate architecture associated with high tension, were more sensitive to perforin than cells grown on softer hydrogel matrices, which adopted a more collapsed morphology. Importantly, target cells on stiff hydrogels were also more sensitive to CTL-mediated killing, implying that the physical status of the membrane affects the outcome of bona fide cytotoxic interactions, as well. Taken together, these observations suggested a model in which synaptic force promotes killing by straining the target cell membrane, thereby facilitating the formation of perforin pores (Figure 3D). The idea that the physical disposition of the synapse is critical for cytotoxicity has interesting implications for immune evasion. Studies have suggested that transformation and malignancy is associated with cellular softening ${ }^{141-143}$; it will therefore be interesting to see whether tumor cells modulate their physical properties in order to circumvent immunemediated attack. 


\section{Concluding remarks}

Over the last decade, a conceptual framework has emerged for measuring and interpreting mechanical forces in immune cells. In general, however, the field remains in its infancy. Our understanding of immunoreceptor mechanotransduction, for example, is limited to antigen receptors and a small number of well-characterized cell adhesion molecules. A substantial amount of intercellular communication in the immune system is mediated by membraneassociated ligands that bind to their receptors within specialized cell-cell contacts like the immunological synapse. The extent to which these interactions and the signaling that results from them are modulated by interfacial forces is largely unknown.

The observation that applied force boosts the activity of perforin within the immunological synapse reveals that immune cells combine mechanical and secretory outputs to maximize the power of their effector responses. This physicochemical synergy, called mechanopotentiation, is conceptually distinct from canonical mechanotransduction, and it represents a previously unappreciated way in which leukocytes use force to transmit information to other cells. It seems likely that force influences immune cell function via a variety of mechanisms, and exploring this diversity will be an interesting topic for future research.

The role of force is best understood in controlled, in vitro systems where it is easily measured. Extending mechanobiological studies into more complex settings, both in vitro and in vivo, will require further development of tools that enable precise physical measurements in living cells. The recent emergence of fluorescent TGTs highlights one possible avenue forward ${ }^{144,145}$, and it will be interesting to see whether probes like these can be incorporated into 3D culture systems and organ preparations. Genetically encoded tension sensor modules have also been developed in which an extendable, force sensitive domain is placed between a Förster resonance energy transfer donor and an acceptor (see Box 1). These modules, when incorporated into cytoskeletal scaffolds and adhesion proteins, have enabled dynamic measurements of cytoskeletal tension in living cells ${ }^{146-148}$. This is very exciting because constructs like this could, in principle, be incorporated into in vivo systems. At the moment, however, these sensors detect only a limited range of forces and have been applied to a limited set of contexts. New probes targeting different physical parameters, such as membrane tension, will be essential for further progress. We can only study what we can measure, and as the field of mechanobiology moves forward, it will be advisable to keep this obvious dictum in mind.

\section{Acknowledgements}

I thank L. Kam and S. Grinstein for advice and discussions. Supported by the NIH-NIAID (R01AI087644) and the NSF (CMMI-1562905).

\section{Glossary}

\section{Slip bond}

A bond whose lifetime decreases with applied force 


\section{Catch bond}

A bond whose lifetime increases up to an optimal applied force, after which it decreases with force

\section{Immunological synapse}

A transient, structurally stereotyped contact formed between immune cells

\section{Focal adhesion}

An force-bearing multiprotein complex that anchors the cortical F-actin cytoskeleton of adherent cells to the substrate

\section{Mechanotransduction}

The conversion of mechanical force into chemical signals

\section{Mechanosensing}

The capacity of cells or molecules to detect physical properties or perturbations

\section{Extravasation}

The movement of leukocytes out of the circulatory system, typically through vessel walls. Also called diapedesis

\section{References}

1. Iskratsch T, Wolfenson $\mathrm{H} \&$ Sheetz MP Appreciating force and shape-the rise of mechanotransduction in cell biology. Nat Rev Mol Cell Biol 15, 825-833, doi:10.1038/nrm3903 (2014). [PubMed: 25355507]

2. Vicente-Manzanares M, Ma X, Adelstein RS \& Horwitz AR Non-muscle myosin II takes centre stage in cell adhesion and migration. Nat Rev Mol Cell Biol 10, 778-790, doi:nrm2786 [pii] 10.1038/nrm2786 (2009). [PubMed: 19851336]

3. Smith A et al. The role of the integrin LFA-1 in T-lymphocyte migration. Immunol Rev 218, 135146, doi:10.1111/j.1600-065X.2007.00537.x (2007). [PubMed: 17624950]

4. Matsumura F Regulation of myosin II during cytokinesis in higher eukaryotes. Trends Cell Biol 15, 371-377, doi:10.1016/j.tcb.2005.05.004 (2005). [PubMed: 15935670]

5. Hui KL, Balagopalan L, Samelson LE \& Upadhyaya A Cytoskeletal forces during signaling activation in Jurkat T-cells. Mol Biol Cell 26, 685-695, doi:10.1091/mbc.E14-03-0830 (2015). [PubMed: 25518938]

6. Basu R et al. Cytotoxic T Cells Use Mechanical Force to Potentiate Target Cell Killing. Cell 165, 100-110, doi:10.1016/j.cell.2016.01.021 (2016). [PubMed: 26924577]

7. Natkanski E et al. B cells use mechanical energy to discriminate antigen affinities. Science 340 , 1587-1590, doi:10.1126/science.1237572 (2013). [PubMed: 23686338]

8. Lammermann $\mathrm{T}$ et al. Rapid leukocyte migration by integrin-independent flowing and squeezing. Nature 453, 51-55, doi:10.1038/nature06887 (2008). [PubMed: 18451854]

9. Jannat RA, Dembo M \& Hammer DA Traction forces of neutrophils migrating on compliant substrates. Biophysical journal 101, 575-584, doi:10.1016/j.bpj.2011.05.040 (2011). [PubMed: 21806925]

10. Toyjanova J, Flores-Cortez E, Reichner JS \& Franck C Matrix confinement plays a pivotal role in regulating neutrophil-generated tractions, speed, and integrin utilization. J Biol Chem 290, 3752 3763, doi:10.1074/jbc.M114.619643 (2015). [PubMed: 25525264]

11. Chesarone MA, DuPage AG \& Goode BL Unleashing formins to remodel the actin and microtubule cytoskeletons. Nat Rev Mol Cell Biol 11, 62-74, doi:nrm2816 [pii] 10.1038/nrm2816 (2010). [PubMed: 19997130] 
12. Goley ED \& Welch MD The ARP2/3 complex: an actin nucleator comes of age. Nat Rev Mol Cell Biol 7, 713-726, doi:10.1038/nrm2026 (2006). [PubMed: 16990851]

13. Yu CH, Law JB, Suryana M, Low HY \& Sheetz MP Early integrin binding to Arg-Gly-Asp peptide activates actin polymerization and contractile movement that stimulates outward translocation. Proc Natl Acad Sci U S A 108, 20585-20590, doi:10.1073/pnas.1109485108 (2011). [PubMed: 22139375]

14. Carman CV et al. Transcellular diapedesis is initiated by invasive podosomes. Immunity 26,784 797, doi:10.1016/j.immuni.2007.04.015 (2007). [PubMed: 17570692]

15. Buccione R, Orth JD \& McNiven MA Foot and mouth: podosomes, invadopodia and circular dorsal ruffles. Nat Rev Mol Cell Biol 5, 647-657, doi:10.1038/nrm1436 (2004). [PubMed: 15366708]

16. Geiger B, Spatz JP \& Bershadsky AD Environmental sensing through focal adhesions. Nat Rev Mol Cell Biol 10, 21-33, doi:10.1038/nrm2593 (2009). [PubMed: 19197329]

17. Gardel ML, Schneider IC, Aratyn-Schaus Y \& Waterman CM Mechanical integration of actin and adhesion dynamics in cell migration. Annual review of cell and developmental biology 26, 315333, doi:10.1146/annurev.cellbio.011209.122036 (2010).

18. Kanchanawong $P$ et al. Nanoscale architecture of integrin-based cell adhesions. Nature 468, 580 584, doi:10.1038/nature09621 (2010). [PubMed: 21107430]

19. Prager-Khoutorsky $\mathrm{M}$ et al. Fibroblast polarization is a matrix-rigidity-dependent process controlled by focal adhesion mechanosensing. Nat Cell Biol 13, 1457-1465, doi:10.1038/ncb2370 (2011). [PubMed: 22081092]

20. Goffin JM et al. Focal adhesion size controls tension-dependent recruitment of alpha-smooth muscle actin to stress fibers. J Cell Biol 172, 259-268, doi:10.1083/jcb.200506179 (2006). [PubMed: 16401722]

21. Galbraith CG, Yamada KM \& Sheetz MP The relationship between force and focal complex development. J Cell Biol 159, 695-705, doi:10.1083/jcb.200204153 (2002). [PubMed: 12446745]

22. Riveline D et al. Focal contacts as mechanosensors: externally applied local mechanical force induces growth of focal contacts by an mDia1-dependent and ROCK-independent mechanism. $\mathrm{J}$ Cell Biol 153, 1175-1186 (2001). [PubMed: 11402062]

23. Wolfenson H, Lavelin I \& Geiger B Dynamic regulation of the structure and functions of integrin adhesions. Developmental cell 24, 447-458, doi:10.1016/j.devcel.2013.02.012 (2013). [PubMed: 23484852]

24. Stanley $\mathrm{P}$ et al. Intermediate-affinity LFA-1 binds alpha-actinin-1 to control migration at the leading edge of the T cell. Embo J 27, 62-75, doi:7601959[pii]10.1038/sj.emboj.7601959 (2008). [PubMed: 18079697]

25. Monks CR, Freiberg BA, Kupfer H, Sciaky N \& Kupfer A Three-dimensional segregation of supramolecular activation clusters in T cells. Nature 395, 82-86 (1998). [PubMed: 9738502]

26. Santos LC et al. Actin polymerization-dependent activation of Cas-L promotes immunological synapse stability. Immunol Cell Biol 94, 981-993, doi:10.1038/icb.2016.61 (2016). [PubMed: 27359298]

27. Ingber DE Cellular mechanotransduction: putting all the pieces together again. FASEB J 20, 811827, doi:10.1096/fj.05-5424rev (2006). [PubMed: 16675838]

28. Orr AW, Helmke BP, Blackman BR \& Schwartz MA Mechanisms of mechanotransduction. Developmental cell 10, 11-20, doi:10.1016/j.devcel.2005.12.006 (2006). [PubMed: 16399074]

29. Pathak MM et al. Stretch-activated ion channel Piezo1 directs lineage choice in human neural stem cells. Proc Natl Acad Sci U S A 111, 16148-16153, doi:10.1073/pnas.1409802111 (2014). [PubMed: 25349416]

30. Lee W et al. Synergy between Piezo1 and Piezo2 channels confers high-strain mechanosensitivity to articular cartilage. Proc Natl Acad Sci U S A 111, E5114-5122, doi:10.1073/pnas.1414298111 (2014). [PubMed: 25385580]

31. Ranade SS et al. Piezo1, a mechanically activated ion channel, is required for vascular development in mice. Proc Natl Acad Sci U S A 111, 10347-10352, doi:10.1073/pnas. 1409233111 (2014). [PubMed: 24958852] 
32. del Rio A et al. Stretching single talin rod molecules activates vinculin binding. Science 323, 638641, doi:10.1126/science.1162912 (2009). [PubMed: 19179532]

33. Elosegui-Artola A et al. Mechanical regulation of a molecular clutch defines force transmission and transduction in response to matrix rigidity. Nat Cell Biol 18, 540-548, doi:10.1038/ncb3336 (2016). [PubMed: 27065098]

34. Dembo M, Torney DC, Saxman K \& Hammer D The reaction-limited kinetics of membrane-tosurface adhesion and detachment. Proceedings of the Royal Society of London. Series B, Containing papers of a Biological character. Royal Society 234, 55-83 (1988).

35. Thomas WE, Vogel V \& Sokurenko E Biophysics of catch bonds. Annual review of biophysics 37, 399-416, doi:10.1146/annurev.biophys.37.032807.125804 (2008).

36. Engler AJ, Sen S, Sweeney HL \& Discher DE Matrix elasticity directs stem cell lineage specification. Cell 126, 677-689, doi:10.1016/j.cell.2006.06.044 (2006). [PubMed: 16923388]

37. Assoian RK \& Klein EA Growth control by intracellular tension and extracellular stiffness. Trends Cell Biol 18, 347-352, doi:10.1016/j.tcb.2008.05.002 (2008). [PubMed: 18514521]

38. Trichet $\mathrm{L}$ et al. Evidence of a large-scale mechanosensing mechanism for cellular adaptation to substrate stiffness. Proc Natl Acad Sci U S A 109, 6933-6938, doi:10.1073/pnas.1117810109 (2012). [PubMed: 22509005]

39. Judokusumo E, Tabdanov E, Kumari S, Dustin ML \& Kam LC Mechanosensing in T lymphocyte activation. Biophysical journal 102, L5-7, doi:10.1016/j.bpj.2011.12.011 (2012). [PubMed: 22339876]

40. Saez A, Buguin A, Silberzan P \& Ladoux B Is the mechanical activity of epithelial cells controlled by deformations or forces? Biophysical journal 89, L52-54, doi:10.1529/biophysj.105.071217 (2005). [PubMed: 16214867]

41. Califano JP \& Reinhart-King CA Substrate Stiffness and Cell Area Predict Cellular Traction Stresses in Single Cells and Cells in Contact. Cell Mol Bioeng 3, 68-75, doi:10.1007/ s12195-010-0102-6 (2010). [PubMed: 21116436]

42. Ghibaudo $\mathrm{M}$ et al. Traction forces and rigidity sensing regulate cell functions. Soft Matter 4, 18361843, doi:10.1039/b804103b (2008).

43. Renkawitz J \& Sixt M Mechanisms of force generation and force transmission during interstitial leukocyte migration. EMBO Rep 11, 744-750, doi:10.1038/embor.2010.147 (2010). [PubMed: 20865016]

44. Yakubenko VP, Lishko VK, Lam SC \& Ugarova TP A molecular basis for integrin alphaMbeta 2 ligand binding promiscuity. J Biol Chem 277, 48635-48642, doi:10.1074/jbc.M208877200 (2002). [PubMed: 12377763]

45. Vorup-Jensen T et al. Exposure of acidic residues as a danger signal for recognition of fibrinogen and other macromolecules by integrin alphaXbeta2. Proc Natl Acad Sci U S A 102, 1614-1619, doi:10.1073/pnas.0409057102 (2005). [PubMed: 15665082]

46. Renkawitz J et al. Adaptive force transmission in amoeboid cell migration. Nat Cell Biol 11, 14381443, doi:10.1038/ncb1992 (2009). [PubMed: 19915557]

47. Vicente-Manzanares M, Choi CK \& Horwitz AR Integrins in cell migration--the actin connection. J Cell Sci 122, 199-206, doi:10.1242/jcs.018564 (2009). [PubMed: 19118212]

48. Lin CH \& Forscher P Growth cone advance is inversely proportional to retrograde F-actin flow. Neuron 14, 763-771 (1995). [PubMed: 7536426]

49. Pollard TD \& Borisy GG Cellular motility driven by assembly and disassembly of actin filaments. Cell 112, 453-465 (2003). [PubMed: 12600310]

50. Ponti A, Machacek M, Gupton SL, Waterman-Storer CM \& Danuser G Two distinct actin networks drive the protrusion of migrating cells. Science 305, 1782-1786, doi:10.1126/science.1100533 (2004). [PubMed: 15375270]

51. Medeiros NA, Burnette DT \& Forscher P Myosin II functions in actin-bundle turnover in neuronal growth cones. Nat Cell Biol 8, 215-226, doi:10.1038/ncb1367 (2006). [PubMed: 16501565]

52. Wilson CA et al. Myosin II contributes to cell-scale actin network treadmilling through network disassembly. Nature 465, 373-377, doi:10.1038/nature08994 (2010). [PubMed: 20485438]

53. Sanchez-Madrid F \& Serrador JM Bringing up the rear: defining the roles of the uropod. Nat Rev Mol Cell Biol 10, 353-359, doi:10.1038/nrm2680 (2009). [PubMed: 19373240] 
54. Eddy RJ, Pierini LM, Matsumura F \& Maxfield FR Ca2+-dependent myosin II activation is required for uropod retraction during neutrophil migration. J Cell Sci 113 ( Pt 7), 1287-1298 (2000). [PubMed: 10704379]

55. Luo BH, Carman CV \& Springer TA Structural basis of integrin regulation and signaling. Annu Rev Immunol 25, 619-647, doi:10.1146/annurev.immunol.25.022106.141618 (2007). [PubMed: 17201681]

56. Kim C, Ye F \& Ginsberg MH Regulation of integrin activation. Annual review of cell and developmental biology 27, 321-345, doi:10.1146/annurev-cellbio-100109-104104 (2011).

57. Astrof NS, Salas A, Shimaoka M, Chen J \& Springer TA Importance of force linkage in mechanochemistry of adhesion receptors. Biochemistry 45, 15020-15028, doi:10.1021/bi061566o (2006). [PubMed: 17154539]

58. Friedland JC, Lee MH \& Boettiger D Mechanically activated integrin switch controls alpha5beta1 function. Science 323, 642-644, doi:10.1126/science.1168441 (2009). [PubMed: 19179533]

59. Woolf $\mathrm{E}$ et al. Lymph node chemokines promote sustained $\mathrm{T}$ lymphocyte motility without triggering stable integrin adhesiveness in the absence of shear forces. Nat Immunol 8, 1076-1085, doi:10.1038/ni1499 (2007). [PubMed: 17721537]

60. Kong F, Garcia AJ, Mould AP, Humphries MJ \& Zhu C Demonstration of catch bonds between an integrin and its ligand. J Cell Biol 185, 1275-1284, doi:10.1083/jcb.200810002 (2009). [PubMed: 19564406]

61. Chen W, Lou J \& Zhu C Forcing switch from short- to intermediate- and long-lived states of the alphaA domain generates LFA-1/ICAM-1 catch bonds. J Biol Chem 285, 35967-35978, doi: 10.1074/jbc.M110.155770 (2010). [PubMed: 20819952]

62. Rosetti F et al. A Lupus-Associated Mac-1 Variant Has Defects in Integrin Allostery and Interaction with Ligands under Force. Cell reports, doi:10.1016/j.celrep.2015.02.037 (2015).

63. Case LB \& Waterman CM Integration of actin dynamics and cell adhesion by a three-dimensional, mechanosensitive molecular clutch. Nat Cell Biol 17, 955-963, doi:10.1038/ncb3191 (2015). [PubMed: 26121555]

64. Smith LA, Aranda-Espinoza H, Haun JB, Dembo M \& Hammer DA Neutrophil traction stresses are concentrated in the uropod during migration. Biophysical journal 92, L58-60, doi:10.1529/ biophysj.106.102822 (2007). [PubMed: 17218464]

65. Dixit N, Yamayoshi I, Nazarian A \& Simon SI Migrational guidance of neutrophils is mechanotransduced via high-affinity LFA-1 and calcium flux. J Immunol 187, 472-481, doi: 10.4049/jimmunol.1004197 (2011). [PubMed: 21632714]

66. Green CE et al. Dynamic shifts in LFA-1 affinity regulate neutrophil rolling, arrest, and transmigration on inflamed endothelium. Blood 107, 2101-2111, doi:10.1182/ blood-2005-06-2303 (2006). [PubMed: 16269618]

67. Ricart BG, Yang MT, Hunter CA, Chen CS \& Hammer DA Measuring traction forces of motile dendritic cells on micropost arrays. Biophysical journal 101, 2620-2628, doi:10.1016/j.bpj. 2011.09.022 (2011). [PubMed: 22261049]

68. Hind LE, Dembo M \& Hammer DA Macrophage motility is driven by frontal-towing with a force magnitude dependent on substrate stiffness. Integr Biol (Camb) 7, 447-453, doi:10.1039/ c4ib00260a (2015). [PubMed: 25768202]

69. Kozlov MM \& Mogilner A Model of polarization and bistability of cell fragments. Biophysical journal 93, 3811-3819, doi:10.1529/biophysj.107.110411 (2007). [PubMed: 17704154]

70. Houk AR et al. Membrane tension maintains cell polarity by confining signals to the leading edge during neutrophil migration. Cell 148, 175-188, doi:10.1016/j.cell.2011.10.050 (2012). [PubMed: 22265410]

71. Keren K et al. Mechanism of shape determination in motile cells. Nature 453, 475-480, doi: 10.1038/nature06952 (2008). [PubMed: 18497816]

72. Diz-Munoz A et al. Membrane Tension Acts Through PLD2 and mTORC2 to Limit Actin Network Assembly During Neutrophil Migration. PLoS Biol 14, e1002474, doi:10.1371/journal.pbio. 1002474 (2016). [PubMed: 27280401]

73. Ley K The role of selectins in inflammation and disease. Trends Mol Med 9, 263-268 (2003). [PubMed: 12829015] 
74. Finger EB et al. Adhesion through L-selectin requires a threshold hydrodynamic shear. Nature 379 , 266-269, doi:10.1038/379266a0 (1996). [PubMed: 8538793]

75. Lawrence MB, Kansas GS, Kunkel EJ \& Ley K Threshold levels of fluid shear promote leukocyte adhesion through selectins (CD62L,P,E). J Cell Biol 136, 717-727 (1997). [PubMed: 9024700]

76. Marshall BT et al. Direct observation of catch bonds involving cell-adhesion molecules. Nature 423, 190-193, doi:10.1038/nature01605 (2003). [PubMed: 12736689]

77. Yago $\mathrm{T}$ et al. Catch bonds govern adhesion through L-selectin at threshold shear. J Cell Biol 166, 913-923, doi:10.1083/jcb.200403144 (2004). [PubMed: 15364963]

78. Thelen M \& Stein JV How chemokines invite leukocytes to dance. Nat Immunol 9, 953-959, doi:ni.f.207 [pii] 10.1038/ni.f.207 (2008). [PubMed: 18711432]

79. Shamri R et al. Lymphocyte arrest requires instantaneous induction of an extended LFA-1 conformation mediated by endothelium-bound chemokines. Nat Immunol 6, 497-506, doi:ni1194 [pii] 10.1038/ni1194 (2005). [PubMed: 15834409]

80. Alon R \& Ley K Cells on the run: shear-regulated integrin activation in leukocyte rolling and arrest on endothelial cells. Curr Opin Cell Biol 20, 525-532, doi:10.1016/j.ceb.2008.04.003 (2008). [PubMed: 18499427]

81. Zhu J et al. Structure of a complete integrin ectodomain in a physiologic resting state and activation and deactivation by applied forces. Mol Cell 32, 849-861, doi:10.1016/j.molcel. 2008.11.018 (2008). [PubMed: 19111664]

82. Nordenfelt P, Elliott HL \& Springer TA Coordinated integrin activation by actin-dependent force during T-cell migration. Nat Commun 7, 13119, doi:10.1038/ncomms13119 (2016). [PubMed: 27721490]

83. Sarangapani KK et al. Regulation of catch bonds by rate of force application. J Biol Chem 286, 32749-32761, doi:10.1074/jbc.M111.240044 (2011). [PubMed: 21775439]

84. Klopocki AG et al. Replacing a lectin domain residue in L-selectin enhances binding to P-selectin glycoprotein ligand-1 but not to 6-sulfo-sialyl Lewis x. J Biol Chem 283, 11493-11500, doi: 10.1074/jbc.M709785200 (2008). [PubMed: 18250165]

85. Nourshargh S \& Alon R Leukocyte migration into inflamed tissues. Immunity 41, 694-707, doi: 10.1016/j.immuni.2014.10.008 (2014). [PubMed: 25517612]

86. Sage PT et al. Antigen recognition is facilitated by invadosome-like protrusions formed by memory/effector T cells. J Immunol 188, 3686-3699, doi:10.4049/jimmunol.1102594 (2012). [PubMed: 22442443]

87. Nourshargh S, Hordijk PL \& Sixt M Breaching multiple barriers: leukocyte motility through venular walls and the interstitium. Nat Rev Mol Cell Biol 11, 366-378, doi:10.1038/nrm2889 (2010). [PubMed: 20414258]

88. Rabodzey A, Alcaide P, Luscinskas FW \& Ladoux B Mechanical forces induced by the transendothelial migration of human neutrophils. Biophysical journal 95, 1428-1438, doi:10.1529/ biophysj.107.119156 (2008). [PubMed: 18390614]

89. Thiam HR et al. Perinuclear Arp2/3-driven actin polymerization enables nuclear deformation to facilitate cell migration through complex environments. Nat Commun 7, 10997, doi:10.1038/ ncomms10997 (2016). [PubMed: 26975831]

90. Davidson PM, Denais C, Bakshi MC \& Lammerding J Nuclear deformability constitutes a ratelimiting step during cell migration in 3-D environments. Cell Mol Bioeng 7, 293-306, doi: 10.1007/s12195-014-0342-y (2014). [PubMed: 25436017]

91. Raab M et al. ESCRT III repairs nuclear envelope ruptures during cell migration to limit DNA damage and cell death. Science 352, 359-362, doi:10.1126/science.aad7611 (2016). [PubMed: 27013426]

92. Denais CM et al. Nuclear envelope rupture and repair during cancer cell migration. Science 352, 353-358, doi:10.1126/science.aad7297 (2016). [PubMed: 27013428]

93. Charras G \& Paluch E Blebs lead the way: how to migrate without lamellipodia. Nat Rev Mol Cell Biol 9, 730-736, doi:10.1038/nrm2453 (2008). [PubMed: 18628785]

94. Chabaud $\mathrm{M}$ et al. Cell migration and antigen capture are antagonistic processes coupled by myosin II in dendritic cells. Nat Commun 6, 7526, doi:10.1038/ncomms8526 (2015). [PubMed: 26109323] 
95. Vargas $\mathrm{P}$ et al. Innate control of actin nucleation determines two distinct migration behaviours in dendritic cells. Nat Cell Biol 18, 43-53, doi:10.1038/ncb3284 (2016). [PubMed: 26641718]

96. Bergert $\mathrm{M}$ et al. Force transmission during adhesion-independent migration. Nat Cell Biol 17, 524529, doi:10.1038/ncb3134 (2015). [PubMed: 25774834]

97. Jacobelli J, Bennett FC, Pandurangi P, Tooley AJ \& Krummel MF Myosin-IIA and ICAM-1 regulate the interchange between two distinct modes of T cell migration. J Immunol 182, 20412050, doi:182/4/2041 [pii] 10.4049/jimmunol.0803267 (2009). [PubMed: 19201857]

98. Franck C, Maskarinec SA, Tirrell DA \& Ravichandran G Three-dimensional traction force microscopy: a new tool for quantifying cell-matrix interactions. PloS one 6, e17833, doi:10.1371/ journal.pone.0017833 (2011). [PubMed: 21468318]

99. Stout DA et al. Mean deformation metrics for quantifying 3D cell-matrix interactions without requiring information about matrix material properties. Proc Natl Acad Sci U S A 113, 28982903, doi:10.1073/pnas.1510935113 (2016). [PubMed: 26929377]

100. Dustin ML, Chakraborty AK \& Shaw AS Understanding the structure and function of the immunological synapse. Cold Spring Harb Perspect Biol 2, a002311, doi:cshperspect.a002311 [pii] 10.1101/cshperspect.a002311 (2010). [PubMed: 20843980]

101. Harwood NE \& Batista FD Early events in B cell activation. Annu Rev Immunol 28, 185-210 (2010). [PubMed: 20192804]

102. O'Connor RS et al. Substrate rigidity regulates human T cell activation and proliferation. J Immunol 189, 1330-1339, doi:10.4049/jimmunol.1102757 (2012). [PubMed: 22732590]

103. Wan $\mathrm{Z}$ et al. B cell activation is regulated by the stiffness properties of the substrate presenting the antigens. J Immunol 190, 4661-4675, doi:10.4049/jimmunol.1202976 (2013). [PubMed: 23554309]

104. Zeng Y et al. Substrate stiffness regulates B-cell activation, proliferation, class switch, and T-cellindependent antibody responses in vivo. Eur J Immunol 45, 1621-1634, doi:10.1002/eji. 201444777 (2015). [PubMed: 25756957]

105. Kim ST et al. The alphabeta T cell receptor is an anisotropic mechanosensor. J Biol Chem 284, 31028-31037, doi:10.1074/jbc.M109.052712 (2009). [PubMed: 19755427]

106. Das DK et al. Force-dependent transition in the T-cell receptor beta-subunit allosterically regulates peptide discrimination and pMHC bond lifetime. Proc Natl Acad Sci U S A 112, 1517 1522, doi:10.1073/pnas.1424829112 (2015). [PubMed: 25605925]

107. Liu B, Chen W, Evavold BD \& Zhu C Accumulation of dynamic catch bonds between TCR and agonist peptide-MHC triggers T cell signaling. Cell 157, 357-368, doi:10.1016/j.cell. 2014.02.053 (2014). [PubMed: 24725404]

108. Aivazian D \& Stern LJ Phosphorylation of T cell receptor zeta is regulated by a lipid dependent folding transition. Nat Struct Biol 7, 1023-1026 (2000). [PubMed: 11062556]

109. Xu $\mathrm{C}$ et al. Regulation of $\mathrm{T}$ cell receptor activation by dynamic membrane binding of the CD3epsilon cytoplasmic tyrosine-based motif. Cell 135, 702-713, doi:10.1016/j.cell.2008.09.044 (2008). [PubMed: 19013279]

110. Lee MS et al. A Mechanical Switch Couples T Cell Receptor Triggering to the Cytoplasmic Juxtamembrane Regions of CD3zetazeta. Immunity 43, 227-239, doi:10.1016/j.immuni. 2015.06.018 (2015). [PubMed: 26231119]

111. Swamy M et al. A Cholesterol-Based Allostery Model of T Cell Receptor Phosphorylation. Immunity 44, 1091-1101, doi:10.1016/j.immuni.2016.04.011 (2016). [PubMed: 27192576]

112. Wan $\mathrm{Z}$ et al. The activation of IgM- or isotype-switched IgG- and IgE-BCR exhibits distinct mechanical force sensitivity and threshold. eLife 4, doi:10.7554/eLife.06925 (2015).

113. Varma R, Campi G, Yokosuka T, Saito T \& Dustin ML T cell receptor-proximal signals are sustained in peripheral microclusters and terminated in the central supramolecular activation cluster. Immunity 25, 117-127 (2006). [PubMed: 16860761]

114. Yi J, Wu XS, Crites T \& Hammer JA, 3rd. Actin retrograde flow and actomyosin II arc contraction drive receptor cluster dynamics at the immunological synapse in Jurkat T cells. Mol Biol Cell 23, 834-852, doi:mbc.E11-08-0731 [pii] 10.1091/mbc.E11-08-0731 (2012). [PubMed: 22219382] 
115. Cai E et al. Visualizing dynamic microvillar search and stabilization during ligand detection by $\mathrm{T}$ cells. Science 356, doi:10.1126/science.aal3118 (2017).

116. Kumari $\mathrm{S}$ et al. Actin foci facilitate activation of the phospholipase $\mathrm{C}$-gamma in primary $\mathrm{T}$ lymphocytes via the WASP pathway. eLife 4, doi:10.7554/eLife.04953 (2015).

117. Pribila JT, Quale AC, Mueller KL \& Shimizu Y Integrins and T cell-mediated immunity. Annu Rev Immunol 22, 157-180, doi:10.1146/annurev.immunol.22.012703.104649 (2004). [PubMed: 15032577]

118. Comrie WA, Babich A \& Burkhardt JK F-actin flow drives affinity maturation and spatial organization of LFA-1 at the immunological synapse. J Cell Biol 208, 475-491, doi:10.1083/jcb. 201406121 (2015). [PubMed: 25666810]

119. Comrie WA, Li S, Boyle S \& Burkhardt JK The dendritic cell cytoskeleton promotes T cell adhesion and activation by constraining ICAM-1 mobility. J Cell Biol 208, 457-473, doi: 10.1083/jcb.201406120 (2015). [PubMed: 25666808]

120. Freeman SA \& Grinstein S Phagocytosis: receptors, signal integration, and the cytoskeleton. Immunol Rev 262, 193-215, doi:10.1111/imr.12212 (2014). [PubMed: 25319336]

121. Goodridge HS et al. Activation of the innate immune receptor Dectin-1 upon formation of a 'phagocytic synapse'. Nature 472, 471-475, doi:10.1038/nature10071 (2011). [PubMed: 21525931]

122. Niedergang F, Di Bartolo V \& Alcover A Comparative Anatomy of Phagocytic and Immunological Synapses. Front Immunol 7, 18, doi:10.3389/fimmu.2016.00018 (2016). [PubMed: 26858721]

123. Freeman SA et al. Integrins Form an Expanding Diffusional Barrier that Coordinates Phagocytosis. Cell 164, 128-140, doi:10.1016/j.cell.2015.11.048 (2016). [PubMed: 26771488]

124. Moller J, Luhmann T, Chabria M, Hall H \& Vogel V Macrophages lift off surface-bound bacteria using a filopodium-lamellipodium hook-and-shovel mechanism. Sci Rep 3, 2884, doi:10.1038/ srep02884 (2013). [PubMed: 24097079]

125. Victora GD \& Nussenzweig MC Germinal centers. Annu Rev Immunol 30, 429-457, doi: 10.1146/annurev-immunol-020711-075032 (2012). [PubMed: 22224772]

126. Nowosad CR, Spillane KM \& Tolar P Germinal center B cells recognize antigen through a specialized immune synapse architecture. Nat Immunol 17, 870-877, doi:10.1038/ni.3458 (2016). [PubMed: 27183103]

127. Olazabal IM et al. Rho-kinase and myosin-II control phagocytic cup formation during CR, but not FcgammaR, phagocytosis. Curr Biol 12, 1413-1418 (2002). [PubMed: 12194823]

128. Araki N, Hatae T, Furukawa A \& Swanson JA Phosphoinositide-3-kinase-independent contractile activities associated with Fcgamma-receptor-mediated phagocytosis and macropinocytosis in macrophages. J Cell Sci 116, 247-257 (2003). [PubMed: 12482911]

129. Dart AE, Tollis S, Bright MD, Frankel G \& Endres RG The motor protein myosin $1 \mathrm{G}$ functions in FcgammaR-mediated phagocytosis. J Cell Sci 125, 6020-6029, doi:10.1242/jcs.109561 (2012). [PubMed: 23038771]

130. Swanson JA et al. A contractile activity that closes phagosomes in macrophages. J Cell Sci 112 ( Pt 3), 307-316 (1999). [PubMed: 9885284]

131. Cox D et al. Myosin X is a downstream effector of PI(3)K during phagocytosis. Nat Cell Biol 4 , 469-477, doi:10.1038/ncb805 (2002). [PubMed: 12055636]

132. Masters TA, Pontes B, Viasnoff V, Li Y \& Gauthier NC Plasma membrane tension orchestrates membrane trafficking, cytoskeletal remodeling, and biochemical signaling during phagocytosis. Proc Natl Acad Sci U S A 110, 11875-11880, doi:10.1073/pnas.1301766110 (2013). [PubMed: 23821745]

133. Keefe $\mathrm{D}$ et al. Perforin triggers a plasma membrane-repair response that facilitates CTL induction of apoptosis. Immunity 23, 249-262, doi:10.1016/j.immuni.2005.08.001 (2005). [PubMed: 16169498]

134. Thiery $\mathbf{J}$ et al. Perforin pores in the endosomal membrane trigger the release of endocytosed granzyme B into the cytosol of target cells. Nat Immunol 12, 770-777, doi:10.1038/ni.2050 (2011). [PubMed: 21685908] 
135. Stinchcombe JC \& Griffiths GM Secretory mechanisms in cell-mediated cytotoxicity. Annual review of cell and developmental biology 23, 495-517 (2007).

136. Bashour KT et al. CD28 and CD3 have complementary roles in T-cell traction forces. Proc Natl Acad Sci U S A 111, 2241-2246, doi:10.1073/pnas.1315606111 (2014). [PubMed: 24469820]

137. Le Floc'h A et al. Annular PIP3 accumulation controls actin architecture and modulates cytotoxicity at the immunological synapse. J Exp Med 210, 2721-2737, doi:10.1084/jem. 20131324 (2013). [PubMed: 24190432]

138. Huang HW, Chen FY \& Lee MT Molecular mechanism of Peptide-induced pores in membranes. Phys Rev Lett 92, 198304 (2004). [PubMed: 15169456]

139. Lee MT, Hung WC, Chen FY \& Huang HW Mechanism and kinetics of pore formation in membranes by water-soluble amphipathic peptides. Proc Natl Acad Sci U S A 105, 5087-5092, doi:10.1073/pnas.0710625105 (2008). [PubMed: 18375755]

140. Polozov IV, Anantharamaiah GM, Segrest JP \& Epand RM Osmotically induced membrane tension modulates membrane permeabilization by class $\mathrm{L}$ amphipathic helical peptides: nucleation model of defect formation. Biophysical journal 81, 949-959, doi:10.1016/ S0006-3495(01)75753-0 (2001). [PubMed: 11463637]

141. Guck J et al. Optical deformability as an inherent cell marker for testing malignant transformation and metastatic competence. Biophysical journal 88, 3689-3698, doi:10.1529/biophysj. 104.045476 (2005). [PubMed: 15722433]

142. Hou HW et al. Deformability study of breast cancer cells using microfluidics. Biomedical microdevices 11, 557-564, doi:10.1007/s10544-008-9262-8 (2009). [PubMed: 19082733]

143. Xu W et al. Cell stiffness is a biomarker of the metastatic potential of ovarian cancer cells. PloS one 7, e46609, doi:10.1371/journal.pone.0046609 (2012). [PubMed: 23056368]

144. Liu Y et al. DNA-based nanoparticle tension sensors reveal that T-cell receptors transmit defined $\mathrm{pN}$ forces to their antigens for enhanced fidelity. Proc Natl Acad Sci U S A 113, 5610-5615, doi: 10.1073/pnas.1600163113 (2016). [PubMed: 27140637]

145. Zhang Y, Ge C, Zhu C \& Salaita K DNA-based digital tension probes reveal integrin forces during early cell adhesion. Nat Commun 5, 5167, doi:10.1038/ncomms6167 (2014). [PubMed: 25342432]

146. Grashoff $\mathrm{C}$ et al. Measuring mechanical tension across vinculin reveals regulation of focal adhesion dynamics. Nature 466, 263-266, doi:10.1038/nature09198 (2010). [PubMed: 20613844]

147. Borghi $\mathrm{N}$ et al. E-cadherin is under constitutive actomyosin-generated tension that is increased at cell-cell contacts upon externally applied stretch. Proc Natl Acad Sci U S A 109, 12568-12573, doi:10.1073/pnas.1204390109 (2012). [PubMed: 22802638]

148. Conway DE et al. Fluid shear stress on endothelial cells modulates mechanical tension across VEcadherin and PECAM-1. Curr Biol 23, 1024-1030, doi:10.1016/j.cub.2013.04.049 (2013). [PubMed: 23684974]

149. Polacheck WJ \& Chen CS Measuring cell-generated forces: a guide to the available tools. Nature methods 13, 415-423, doi:10.1038/nmeth.3834 (2016). [PubMed: 27123817]

150. Liu B, Chen W \& Zhu C Molecular force spectroscopy on cells. Annu Rev Phys Chem 66, 427451, doi:10.1146/annurev-physchem-040214-121742 (2015). [PubMed: 25580628]

151. Cost AL, Ringer P, Chrostek-Grashoff A \& Grashoff C How to Measure Molecular Forces in Cells: A Guide to Evaluating Genetically-Encoded FRET-Based Tension Sensors. Cell Mol Bioeng 8, 96-105, doi:10.1007/s12195-014-0368-1 (2015). [PubMed: 25798203]

152. Evans E, Ritchie K \& Merkel R Sensitive force technique to probe molecular adhesion and structural linkages at biological interfaces. Biophysical journal 68, 2580-2587, doi:10.1016/ S0006-3495(95)80441-8 (1995). [PubMed: 7647261]

153. Dembo M \& Wang YL Stresses at the cell-to-substrate interface during locomotion of fibroblasts. Biophysical journal 76, 2307-2316, doi:10.1016/S0006-3495(99)77386-8 (1999). [PubMed: 10096925]

154. Tan JL et al. Cells lying on a bed of microneedles: an approach to isolate mechanical force. Proc Natl Acad Sci U S A 100, 1484-1489, doi:10.1073/pnas.0235407100 (2003). [PubMed: 12552122] 
155. Wang $X \& \mathrm{Ha} T$ Defining single molecular forces required to activate integrin and notch signaling. Science 340, 991-994, doi:10.1126/science.1231041 (2013). [PubMed: 23704575] 


\section{Box 1}

\section{Measuring cellular forces}

Modern mechanobiology relies on technical approaches that enable the quantification of forces at the single cell and/or single molecule level. Several of the most important strategies are described briefly below. For more comprehensive information, readers are referred to several excellent reviews ${ }^{149-151}$.

\section{Atomic force microscopy (AFM).}

This approach measures minute forces applied to a flexible, calibrated cantilever. The cantilever tip can be pressed into a sample from the top, generating positive deflections that reflect the physical properties of the sample (e.g. stiffness). Alternatively, the cantilever tip and sample surface can be coated with interacting proteins and placed into contact. Subsequent withdrawal of the tip will induce negative deflections that can be used to measure binding strength.

\section{Optical trapping.}

This approach makes use of a focused laser beam to capture a micron-sized particle (e.g. a polystyrene bead) within the imaging field. Particles inside an optical trap are subject to piconewton scale restoring forces, which can be modeled as a simple spring. If the particle in question is tethered to another surface via a biomolecular linkage, the strength of the linkage can be determined by moving the trap away and measuring the displacement of the particle from the trap center, which is directly proportional to the pulling force.

\section{Biomembrane force probe (BFP).}

This system employs red blood cells (RBCs) as sensitive and adjustable force transducers. A stimulatory bead is attached to an RBC, which is then immobilized on the end of a micropipette. Pushing or pulling against the bead induces distortions in the RBC, which behaves as a spring under these conditions. Importantly, the stiffness of the RBC can be modulated over a wide range simply by changing the level of suction within the pipette. This enables measurement of forces ranging from $0.01 \mathrm{pN}$ to $1 \mathrm{nN}^{152}$.

\section{Traction force microscopy (TFM).}

In this system, cells are imaged on deformable substrates containing fluorescent fiducial probes. TFM was initially implemented by embedding fluorescent beads in hydrogel matrices ${ }^{153}$. Bead movements induced by cells in this context are converted into force maps by Fourier techniques using the known elasticity of the gel. TFM has also been implemented using arrays of micropillars made from the deformable plastic polydimethylsiloxane (PDMS) ${ }^{154}$. Cells attached to these arrays induce pillar deflections, which can be converted into force vectors using the known height, width, and composition of the pillars.

\section{Tension-gauge tethers (TGTs).}

In this approach, ligands for receptors of interest are immobilized on surfaces using short DNA duplexes ${ }^{155}$. The rupture force of each duplex is dictated by its sequence, length, 
and the point of junction with the attached ligand. Hence, by using duplexes of increasing strength, the force per receptor required to maintain cell attachment can be determined. In recent years, second generation TGTs have been developed that couple duplex rupture with the unquenching of a fluorophore ${ }^{144,145}$. This enables detection of single molecule pulling events above a given force threshold in real time by live fluorescence imaging.

\section{Intracellular tension sensors.}

In recent years, fluorescent sensors have been developed to report cytoskeletal tension in cells ${ }^{146-148}$. These constructs typically contain a Förster resonance energy transfer (FRET) donor and acceptor separated by a folded peptide sequence that can be extended under tension. Force application above a threshold pulls the donor and acceptor fluorophores apart, decreasing FRET. Constructs like this enable visualization of intracellular forces at subcellular resolution. 
A

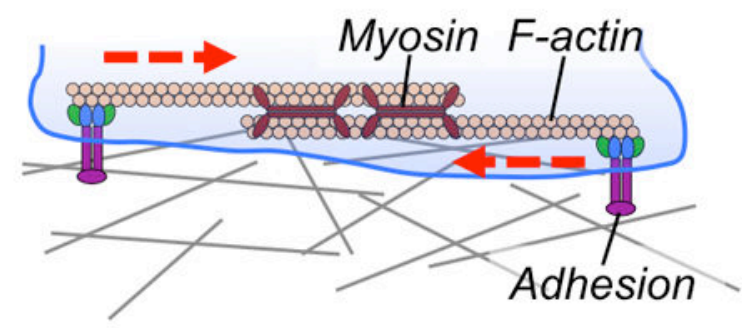

Myosin contractility

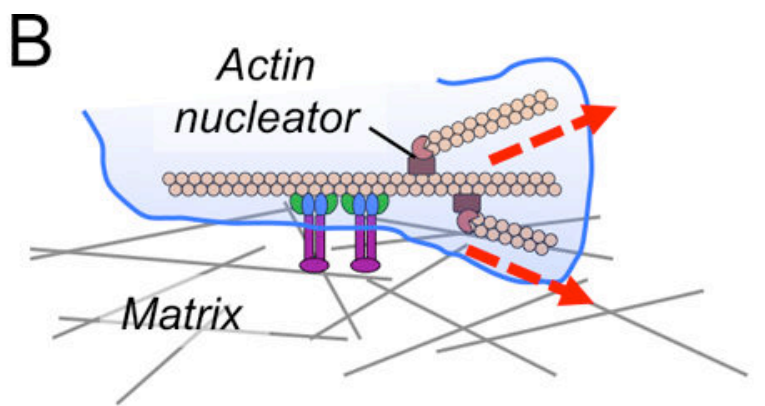

Actin protrusion

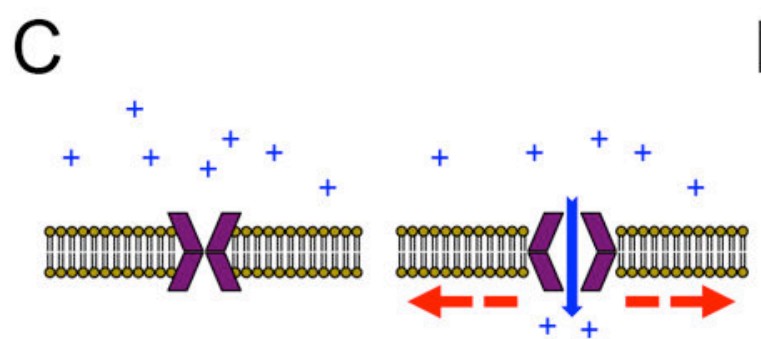

Mechanosensitive channel

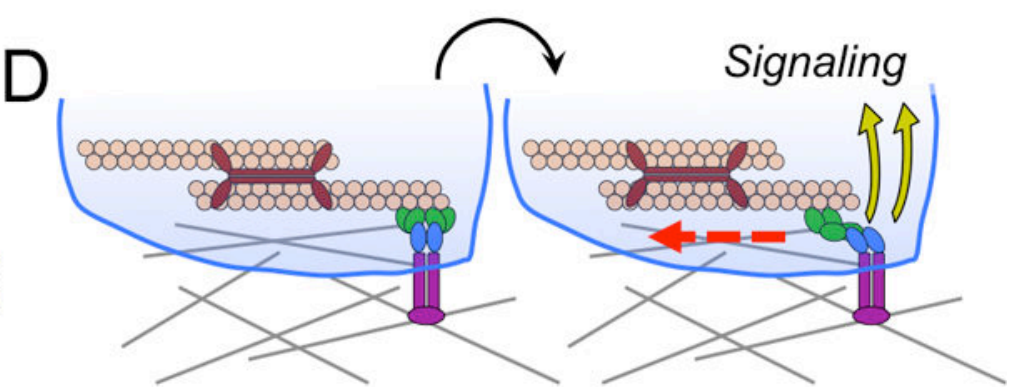

Conformational change

Figure 1. Force exertion and mechanotransduction.

(A-B) Cells exert forces against their environment through myosin contractility (A) and Factin-based protrusion (B). (C) The mechanical gating of a plasma membrane channel by membrane tension. (D) Schematic diagram showing mechanotransduction induced by force dependent conformational change (blue and green components of the adhesion). In all figures, myosin and F-actin are shown as maroon, rabbit-eared oligomers and peach-colored polymers, respectively. Integrin-mediated adhesions are shown in purple, blue, and green. Forces are indicated by red lines. 
A

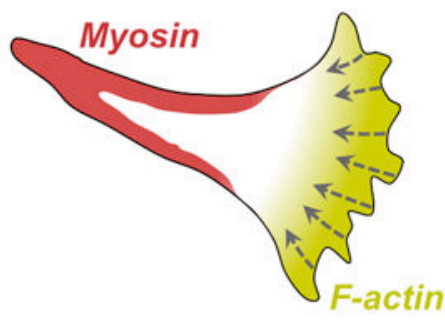

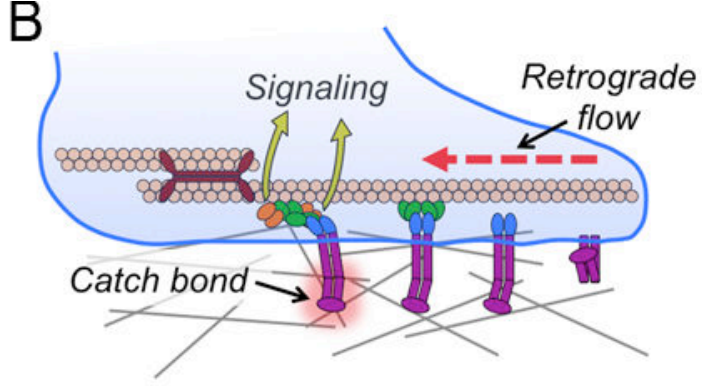

C
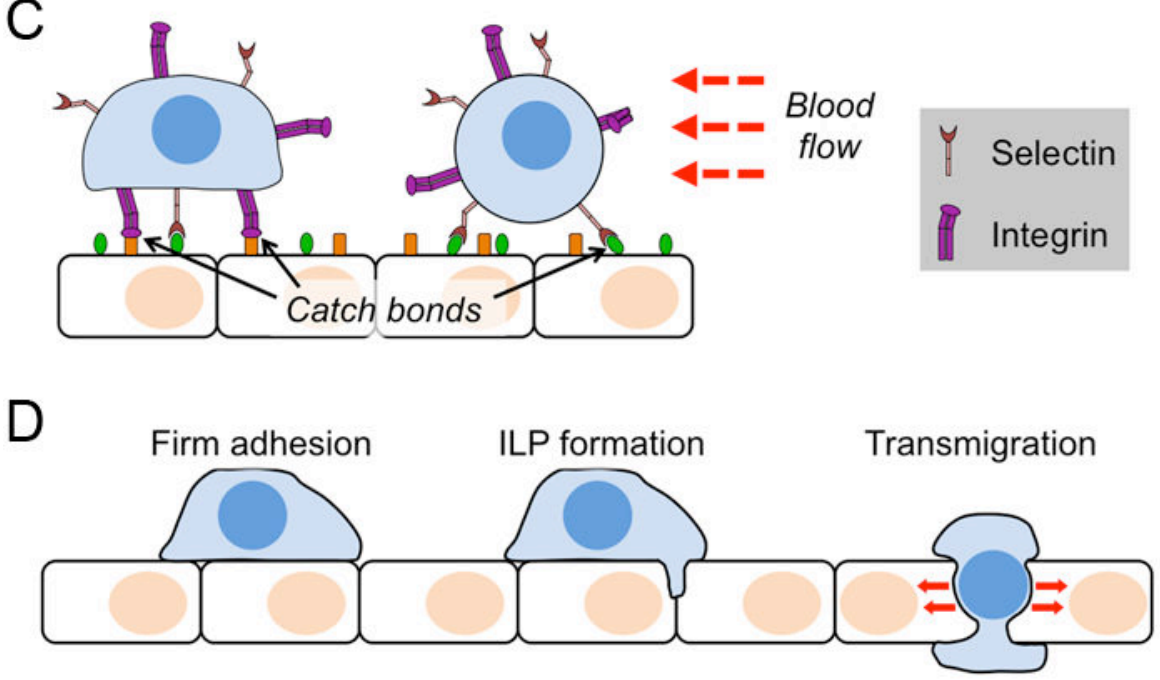

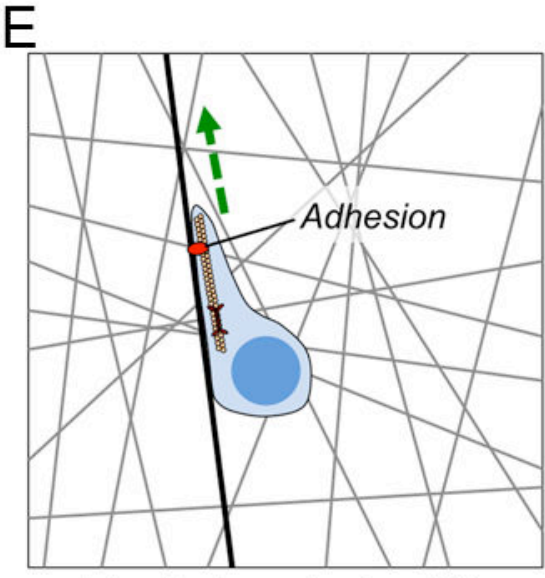

Integrin dependent motility

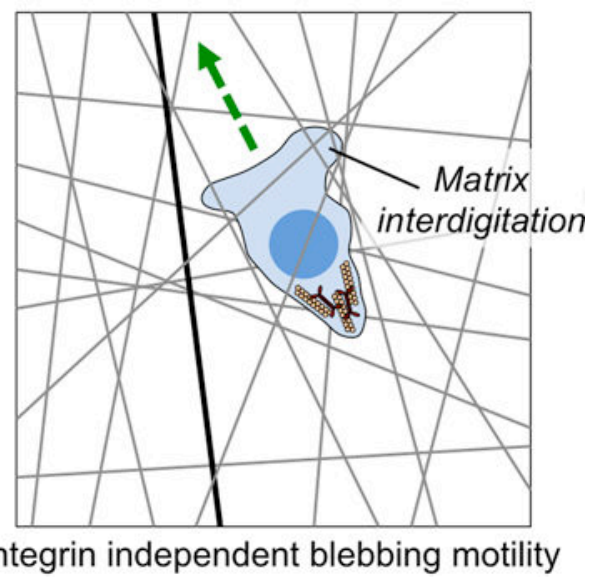

Integrin independent blebbing motility

Figure 2. Mechanical forces in cell migration.

(A) Image depicting the "hand mirror" morphology adopted by leukocytes migrating in two dimensions. (B) Diagram schematizing integrin catch bond and molecular clutch formation during cell migration. Integrins are shown in purple with associated focal adhesion proteins in blue, green, and orange. (C) Selectin and integrin catch bonds mediate leukocyte rolling (right) and firm adhesion (left) to endothelial walls under shear stress. (D) Transendothelial migration is initiated by the formation of an invadosome like protrusion (ILP), followed by the extrusion of the entire cell through the resulting pore. Force exertion is primarily seen in 
the transmigration step. (E) Schematic diagram contrasting adhesion dependent lamellipodial migration (left) and adhesion independent blebbing migration (right). Matrix is indicated by gray lines, and a fiber containing integrin ligands as a black line. Green arrows indicate the direction of motion. In $\mathbf{B}-\mathbf{D}$, red lines indicate force. 

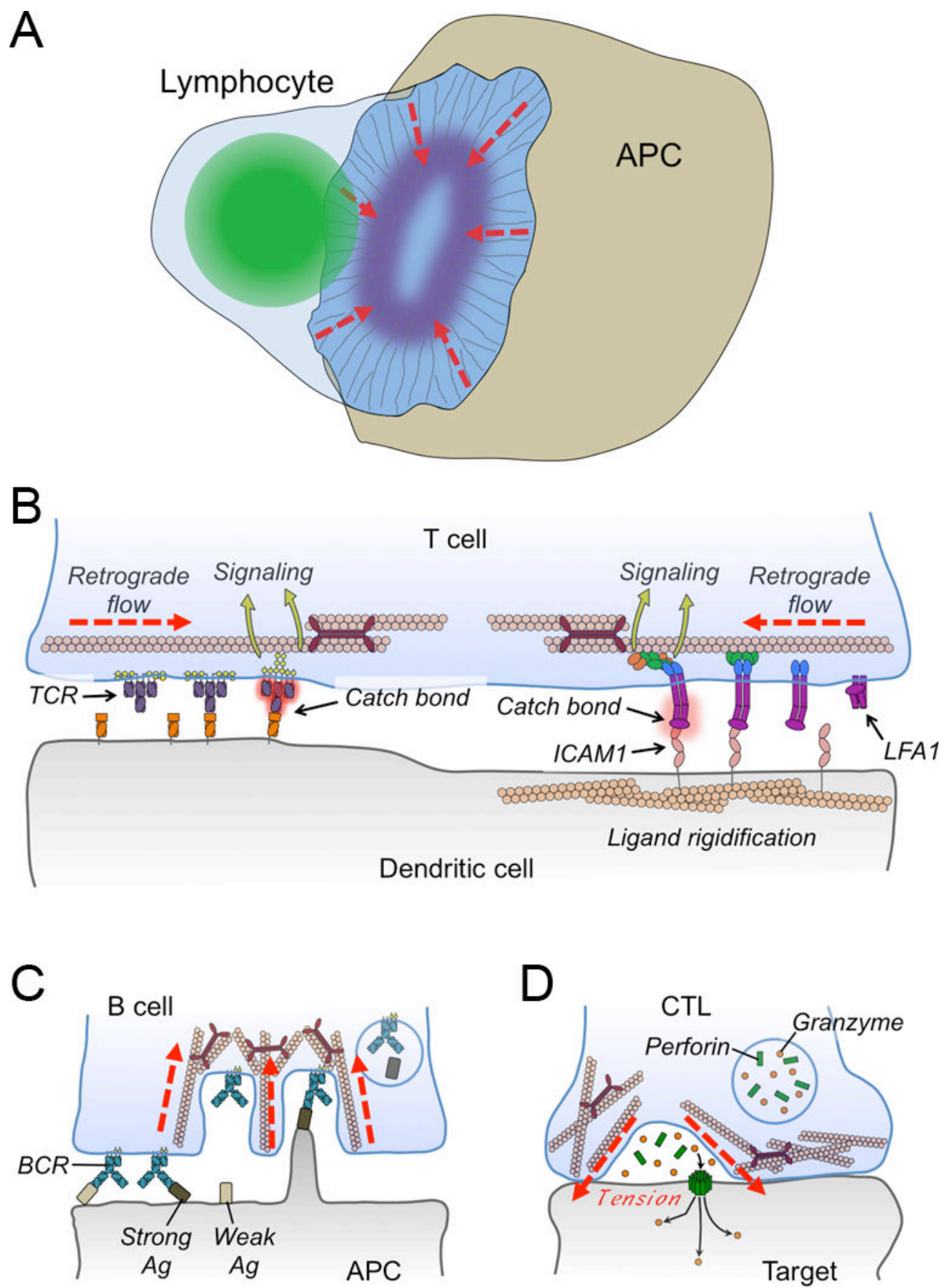

Figure 3. Mechanical forces in immune cell-cell interactions.

(A) Diagram schematizing the lymphocyte immunological synapse. Actin fibers are shown as thin gray lines, the lymphocyte nucleus is green, and integrin clustering is indicated by the purple oval. Dashed red lines indicate the direction of retrograde F-actin flow. (B) Retrograde flow is responsible for driving centripetal motion of TCRs (left) and LFA1 (right), which is thought to contribute to the formation of catch bonds, receptor conformational change, and subsequent mechanotransduction. DCs restrain the movement of cell surface ICAM1 to enhance LFA1 binding and signaling. (C) Myosin-based contractility 
enables B cells to selectively internalize high affinity antigen (Ag). (D) Synaptic forces enhance CTL-mediated killing by applying tension to the target cell, thereby potentiating perforin pore formation in the target cell membrane. In B-D, red lines denote forces. 